\title{
Asthma as a chronic disease of the innate and adaptive immune systems responding to viruses and allergens
}

\author{
Michael J. Holtzman
}

Division of Pulmonary and Critical Care Medicine, Department of Internal Medicine and Department of Cell Biology and Physiology, Washington University School of Medicine, St. Louis, Missouri, USA.

\begin{abstract}
Research on the pathogenesis of asthma has traditionally concentrated on environmental stimuli, genetic susceptibilities, adaptive immune responses, and end-organ alterations (particularly in airway mucous cells and smooth muscle) as critical steps leading to disease. The focus of this cascade has been the response to allergic stimuli. An alternative scheme suggests that respiratory viruses and the consequent response of the innate immune system also drives the development of asthma as well as related inflammatory diseases. This conceptual shift raises the possibility that sentinel cells such as airway epithelial cells, DCs, NKT cells, innate lymphoid cells, and macrophages also represent critical components of asthma pathogenesis as well as new targets for therapeutic discovery. A particular challenge will be to understand and balance the innate as well as the adaptive immune responses to defend the host against acute infection as well as chronic inflammatory disease.
\end{abstract}

\section{Introduction and perspective}

A major goal of medical research is to define the cause and develop the cure for chronic inflammatory disease, traditionally by targeting the adaptive immune system. Convention has also led to a bipartite classification of the adaptive immune system, wherein Th1 cells mediate delayed-type hypersensitivity reactions and selectively produce IL- 2 and IFN- $\gamma$, and Th 2 cells promote B cell-dependent humoral immunity and produce IL-4, IL-5, and IL-13 (1). In the case of asthma, the "Th2 hypothesis" proposes that an upregulated Th2 and a downregulated Th1 response drive the development of disease (Figure 1 and ref. 2). Newer research suggests that increased activity of Th17 (IL-17-producing) cells or Th9 (IL-9-responsive) cells as well as decreased suppressor activity of Tregs (IL-10- and TGF- $\beta$-producing cells) represent additional mechanisms for other subsets of $\mathrm{T}$ cells to contribute to asthma, perhaps in part by skewing the system toward an increased Th2 response (3-5).

The focus on $\mathrm{T}$ cell contributions is derived at least in part from studies of allergen challenge in mouse models of asthma and in humans $(6,7)$. In both cases, allergen challenge is often optimized for a Th2-dominant response. However, this approach may not represent the full clinical spectrum of the disease. The majority of asthmatics may be atopic, but only a minority of those with atopy or atopic disease (including those reactive to inhaled allergen) will ever develop asthma (8). The Th2 hypothesis is therefore challenged to incorporate the possibility that other environmental stimuli might also be essential for asthma pathogenesis. Indeed, there is considerable clinical evidence that respiratory viral infection is also linked to the initial development of asthma as well as exacerbations that might perpetuate the disease. Early clinical work on the role of respiratory viruses in asthma focused on the role of respiratory syncytial virus (RSV) infection in infancy. RSV

Conflict of interest: The author has been a principal investigator for research grants to Washington University from the NIH, Hoffmann-La Roche, and Forest Labs and has received income from Hoffmann-La Roche and Forest Labs.

Citation for this article: J Clin Invest. 2012;122(8):2741-2748. doi:10.1172/JCI60325 is the most common cause of serious respiratory illness in this age group and in severe cases is associated with the subsequent development of a prolonged wheezing illness that in some cases may extend at least to adolescence (9-16). The role of severe RSV infection as a risk factor for asthma in adulthood is less certain but is still under study. Meanwhile, more recent studies have identified infection with human rhinovirus (HRV) as a predominant respiratory pathogen associated with asthma later in life (11,17-21). Other work on influenza A virus (IAV) connects this infection to asthma in children and adults (22-25). Despite extensive association of common types of respiratory viruses with asthma, the available evidence does not yet establish viral infection as a cause of asthma per se, but rather suggests that there may be common susceptibilities to both viral infection and asthma (26). Indeed, atopy itself may predispose toward more severe respiratory viral infection and associated wheezing, particularly in the case of HRV $(21,27)$. In fact, perhaps the strongest predictor of subsequent asthma is the concordance of atopy and severe respiratory viral infection, suggesting that virus-allergen interaction is at work in at least some asthmatics $(19,21,28,29)$. The proof of a causal role for virus infection in asthma must therefore depend on better experimental models of the process and ultimately on effective antiviral measures that serve to lessen the acute infectious illness as well as the subsequent chronic inflammatory disease in humans.

In response to this issue, adherence to the Th2 hypothesis invokes an additional hygiene hypothesis, wherein a lack of exposure to viruses (and/or other inhaled and ingested environmental "dirt" from bacteria and parasites) in modern society leads to an overactive Th2 (allergic) and an underactive Th1 (antiviral) system (30-32). However, even with this hypothetical addendum, the Th2 hypothesis still misses key immune components of asthma (33-35). For example, it is possible to define a positive rather than a negative relationship between viral infection and experimental as well as natural asthma. In addition, increased susceptibility to respiratory viral infection might be detectable even at birth, and perhaps most significantly, as a deficiency of the innate immune system, independent of the $\mathrm{T}$ cell response (36). Moreover, from 


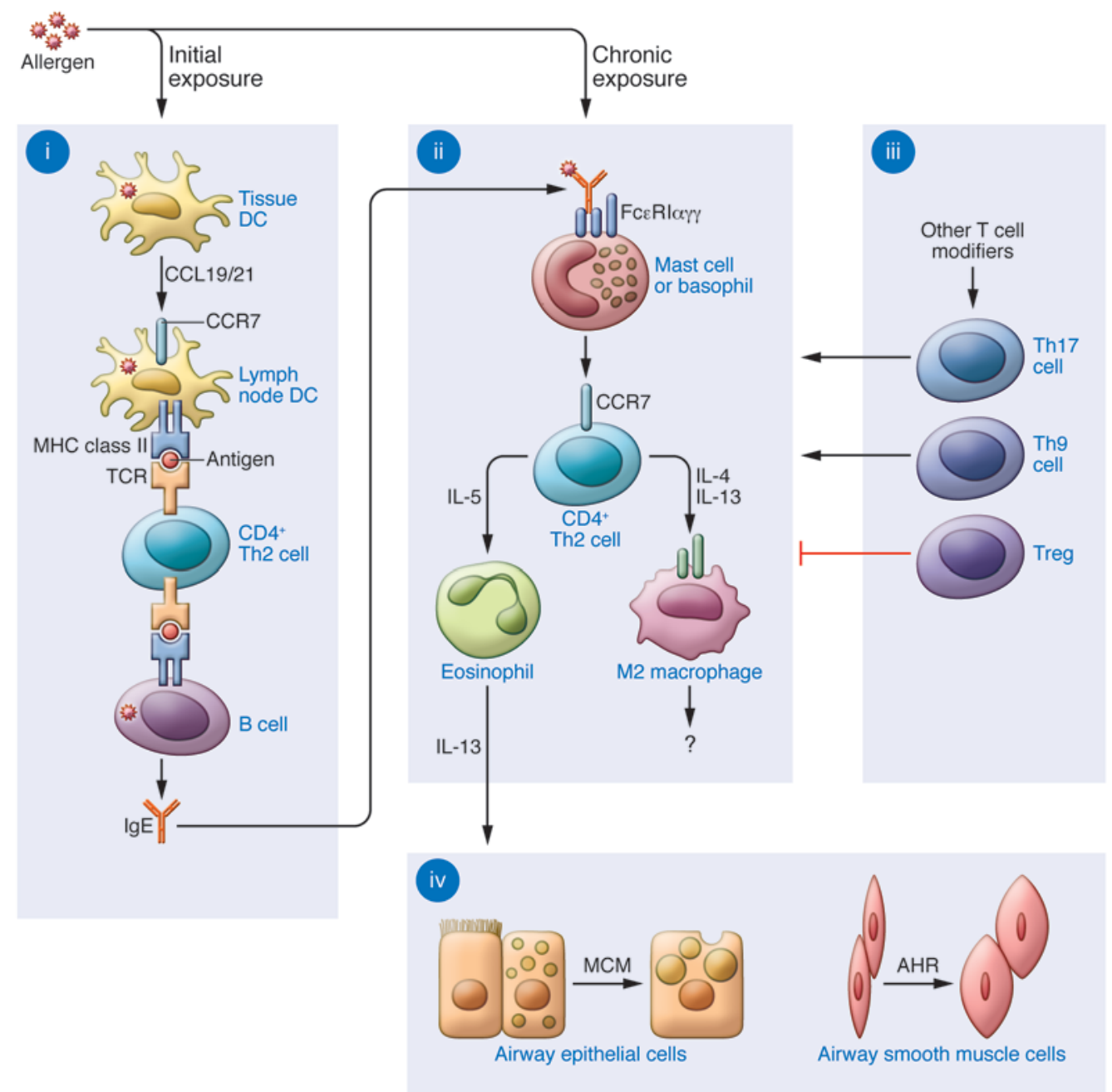

\section{Figure 1}

Immune pathways leading to allergic lung disease. (i) Initial allergen exposure leads to uptake by lung conventional DCs and their migration to regional lymph nodes using CCL19/21-CCR7 interactions. In the nodes, DCs regulate MHC class II-dependent generation of CD4+ Th2 cells and consequent B cell (and, in turn, plasma cell) production of allergen-specific IgE. (ii) Chronic allergen exposure causes IgE cross-linking and FceRI signaling, leading to activation of mast cells (and likely basophils and other cell types), with consequent recruitment of Th2 effector cells to the airway. Th2 cell production of IL-4 and/or IL-13 leads to alternatively activated macrophagedifferentiation, while IL-5 generation leads to eosinophil accumulation and further IL-13 production in the airway. (iii) Additional T cell subsets that regulate the allergic response include Th17, Th9, and Tregs that may influence the Th2 response and may act independently of this response as well. (iv) IL-13 (as well as other cytokines) drive mucous cell metaplasia (MCM) and airway hyperreactivity (AHR) that are characteristic of allergic asthma. Modified with permission from the American Journal of Respiratory Cell and Molecular Biology (140).

a practical perspective, the Th2 hypothesis has led to a focused and sometimes dogmatic approach to diagnosis and therapy of asthma. A few of these therapeutic approaches, such as leukotriene receptor antagonists and anti-IgE antibodies, have achieved limited acceptance $(37,38)$. Others, for example, IL-4, IL-5, and IL-13 inhibition, show some level of benefit in a subset of asthmatics based on initial clinical studies (39-42). However, these approaches may have succeeded at least in part because they also happen to inadvertently target the innate immune system. In either case, the rather limited means to significantly prevent and/or cure the inflammatory process in asthma, particularly severe asthma, remains disappointing (35).

This review will revisit the immune component of asthma and summarize some of the advances that led to a substantial revi- sion of our understanding of the pathogenic mechanism. This includes the unexpectedly major role of the innate immune system in the pathogenesis of experimental asthma and the emerging evidence that similar events might occur in humans with chronic obstructive lung disease due to asthma as well as chronic obstructive pulmonary disease (COPD). It now appears possible that the innate immune system may function independently of the adaptive immune system in some cases and in synergy with it in others, and the relative contributions of the two systems may explain disease heterogeneity among patients. In addition, we discuss how these immune insights into the response to respiratory viruses could lead to new therapeutic strategies and thereby prevent acute infectious illness and chronic inflammatory disease of the pulmonary airways in the future. 


\section{Epithelial cells and viral disease}

Respiratory viruses likely make initial contact with at least three critical cell populations in the airway: mucosal epithelial cells, which provide a home to most of the virus; airspace and tissue macrophages, which remove most of the virus; and resident and migratory DCs, which process and transport some of the virus to arm the immune system. This paradigm portrays the epithelial cell as a passive victim in the immune response, but an alternative view is that airway epithelial cells (and epithelial barrier cells in general) are active sentinels. This idea was derived originally from circumstantial evidence and intuition during studies of experimental asthma (43). We now recognize that airway epithelial cells constitute a specialized system that coordinates an intricate battle with the invading microbe, particularly in the case of respiratory viral infection (44). A series of overlapping and redundant molecular pathways (representing systems biology at its best) are implicated in deciding which cells shall live and which shall undergo apoptosis, necrosis, or autophagy. Amidst this complexity, one pathway that emerges as critical for host defense and contribution to asthma is based on IFN signal transduction. Thus, despite being the primary residence for respiratory viruses (or perhaps because of it), airway epithelial cells are specially primed for potent IFN production and consequent expression of hundreds of IFN-stimulated genes (ISGs). These ISGs encode proteins that control viral level directly by inhibiting viral production or indirectly by activating immune cells and killing host cells harboring the virus (45). Despite the complexity of the IFN-signaling network, it invariably relies on STAT1 as a master regulator of ISG expression $(46,47)$. If this network is genetically defective (e.g., due to STAT1 deficiency) in mice or man, the host often succumbs to lethal viral infection (48). Moreover, the functional level of this antiviral response, as judged by the amount of IFN production and signaling, appears to correlate with the degree of host protection. For example, the level of IFN $\gamma$ gene induction in response to RSV infection in cord blood monocytes can predict the likelihood of respiratory tract infection in the first year of life (36). In this case, the lower the IFN production, the more likely the child is to develop a respiratory illness. This finding may complement downregulation of the IFN response found in T cells in allergy and asthma (16, 17, 49-56). In either case, a deficiency of IFN-dependent control of respiratory viruses might render an individual more susceptible to developing or exacerbating asthma.

Whether there is a defect in IFN-dependent control of respiratory viruses at the level of airway epithelial cells and whether this defect causes asthma remain less certain. Work in experimental models suggests that a deficiency of IFN signaling in airway epithelial cells will compromise host defense against respiratory viruses (44, 46, 57-59). Moreover, these models and epidemiologic studies indicate that a more severe infection is more likely to lead to asthma. Some studies showing a deficiency in IFN- $\beta$ and IFN- $\lambda$ production in response to HRV inoculation in airway epithelial cells cultured from asthmatic versus normal subjects suggest that these observations translate to human patients $(60,61)$. Other studies suggest that abnormal IFN signaling is also a cause of asthma (62), and genetic analysis has demonstrated ISG linkage in asthma subjects $(63,64)$. However, others have found that control of viral replication and production of IFN may also be defective in airway epithelial cells from patients with other types of inflammatory airway disease, e.g., COPD and cystic fibrosis (65-67). Moreover, even in the case of asthma, not all reports agree on a defect in IFN-dependent control of viral replication ex vivo or in vivo $(18,68-72)$. A better understanding of the issue will require a comprehensive analysis of type I, II, and/or III IFN level and/or signaling activity during viral infection in asthma versus normal subjects, but this has been difficult to achieve in part because of the logistical challenge of quantifying IFN and corresponding viral load in vivo. As described below, however, this situation is still an opportunity for anti-asthma intervention as well as a precedent for defining other epithelial factors that might control viral disease. Thus, airway epithelial cells may also be a source of intrinsic antiviral factors and immunoregulatory cytokines, neither of which requires IFN production.

\section{Innate immune cells and viral disease}

With some degree of irony, acceptance of the hypothesis that the innate immune system positively stimulates the development of asthma came with the understanding that airway epithelial cells might also be a source of Th2 cytokines. In particular, evidence arose that epithelial production of IL-25, thymic stromal lymphopoietin (TSLP), and/or IL-33 might drive Th2 responses (particularly in the form of IL-13 production) and in turn result in disease traits that are characteristic of asthma (73-84). This issue naturally led to the search for innate immune cells that might respond to epithelial cytokines with an increase in IL-13 production. A series of reports identified lineage-negative lymphoid cells (analogous to those found in the gut) that responded to IL-25 and IL-33 by producing IL-13 and IL-5 (85-88). Follow-up reports noted that these relatively rare cells (variously named non-B/ non-T cells, natural helper cells, nuocytes, or innate lymphoid cells) constitute the major source of IL-13 in the lung after challenge with an allergen (ovalbumin) or the helminth $N$. brasiliensis $(89,90)$. This finding is surprising given the usual abundance of eosinophils in these conditions and the high-level capability of eosinophils for IL-13 production. A related report proposed that innate lymphoid cells also mediate the airway inflammation and hyperreactivity that occur just one day after IAV infection in mice (91). In this case, the virus activates alveolar macrophages to generate IL-33 that stimulates innate lymphoid cells to produce IL-13. However, we are still missing an experiment that selectively blocks endogenous innate lymphoid cells and demonstrates the contribution of the native cell population to the asthma phenotype. This step will be critical to use these immune cell events as biomarkers and therapeutic targets in humans.

Another noteworthy drawback to studies of asthma is the frequent lack of physiological relevance of experimental models and the attendant requirement to translate findings in the model to humans with asthma. For example, an obvious experiment in an animal model would be to explore the possible connection between severe RSV bronchiolitis and asthma. However, a human pathogen such as RSV exhibits only limited replication in a rodent host (92), perhaps explaining the relatively short-lived effect of RSV on airway inflammation and dysfunction in mice. Such an outcome does not fit with the full spectrum of clinical experience in humans, in which the effect of RSV on airway inflammation and the development of postviral asthma might be delayed or might last for weeks, months, or even years. Similarly, despite genetic manipulation to favor infection, HRV also exhibits a relatively low level of replication and consequent illness in the mouse model $(93,94)$. Perhaps this experimental difficulty will improve with the isolation of a more aggressive group of HRV-C 
species (95). Nonetheless, HRV as well as RSV and IAV infection have all been demonstrated to worsen allergen-induced asthma in experimental models $(93,94,96-98)$, raising the possibility that virus-allergen synergy is an initiator or perpetuator of disease in childhood and adulthood.

Meanwhile, there was still a need to develop a model of viral infection that resulted in long-term experimental asthma. Toward that end, it is possible to remove the obstacle in host range for RSV (and other human pathogens) by substituting the corresponding mouse paramyxovirus known as mouse parainfluenza virus type I or Sendai virus $(\mathrm{SeV})$. This alternative provides for a model that mimics cardinal features of the human disease process, including acute bronchiolitis (as found in RSV-infected infants) followed by chronic (perhaps lifelong) airway inflammation, mucus overproduction, and hyperreactivity that depend on genetic susceptibility (as found in asthmatic children, teenagers, and adults) (99-101). The $\mathrm{SeV}$ mouse model has proven useful for understanding immunological events leading to acute illness and chronic airway disease after viral infection (Figure 2). In terms of acute postviral illness, the model has allowed for more complete definition of the innate and adaptive immune response that controls and then clears infectious respiratory virus. As introduced above, there is an emerging understanding of precisely how airway epithelial cells participate in this aspect of host defense. In particular, the capacity of airway epithelial cells for IFN production and signaling is emerging as a key requirement for containing viral infection and preventing postviral asthma $(46,102)$. In concert with the epithelial contribution for viral control, there is also a better awareness of the role of the lung macrophage in the antiviral host response. For example, an unexpected action of the chemokine CCL5 allows the macrophage to avoid virus-induced cell death and thereby continue the task of viral clearance (103). We also understand at least some of the pieces for how this innate response cues the subsequent adaptive response to achieve full clearance of the virus and protection again similar viruses in the future. Critical elements include DC arming of $\mathrm{CD}^{+}\left(\right.$and $\left.\mathrm{CD}^{+}\right) \mathrm{T}$ cell cytotoxicity for lysis of infected cells as well as $\mathrm{CD}^{+} \mathrm{T}$ cell help for B cell and plasma cell antiviral antibody production (104-106).

From the perspective of asthma, however, the real advantage of the $\mathrm{SeV}$ mouse model is that it manifests the pattern of airway inflammation, hyperreactivity, and mucus overproduction that develop and persist long after clearance of infectious virus. The extended time course of this postviral process therefore better mimics the clinical experience that links severe RSV bronchiolitis to a long-term wheezing illness in early childhood, and perhaps to the chronic obstructive lung disease that makes up the spectrum of asthma and (as we are learning) COPD in later life as well. The model has revealed two new potentially asthmagenic pathways: one leading from conventional DCs to Th2 cells $(107,108)$, and another from APCs (DCs or macrophages) to invariant NKT (iNKT) cells to alternatively activated (M2) monocytes and macrophages (109). The first pathway is responsible for the early/transient disease that appears at 3 weeks after viral inoculation and features IFN- $\alpha / \beta$ dependent expression and IgE-dependent activation of the highaffinity IgE receptor (FceRI) on DCs and consequent CCL28 production to recruit IL-13-producing $\mathrm{CD}^{+} \mathrm{T}$ cells to the airways (107). The connection between IFN and DCs requires a CD11bdependent interaction with a CD $49^{+}$subset of PMNs (108). This pathway thereby contains components of both the innate and adaptive immune systems. The second pathway is responsible for the late/chronic disease that develops fully at 7 weeks after inoculation and is driven instead by an innate immune response that relies on iNKT cells that are programmed to activate macrophages to produce IL-13 $(109,110)$. The interaction between iNKT cells and macrophages depends on contact between the semi-invariant V $\alpha 14$ J 18 -TCR on lung iNKT cells and the oligomorphic MHClike protein CD1d on macrophages as well as NKT cell production of IL-13 that binds to the IL-13 receptor (IL-13R) on the macrophage (109). This pathway appears to function independent of the adaptive immune system. Each of these pathways provides for new biomarkers and therapeutic targets for clinical application.

A critical next step for this approach (and others like it) is to determine whether similar abnormalities of the innate immune system are also found in asthma and in forms of COPD that may also manifest airway inflammation, mucus overproduction, and hyperreactivity. This translation is just beginning, but it has been shown that the high-affinity IgE receptor is found on human DCs in peripheral blood samples from children as early as one year of age (111). Analysis of the second immune axis is challenging due to the rarity of NKT cells and the need for specific biomarkers of M2 macrophages in lung tissue. These problems can be overcome in part by using whole-lung explants from patients undergoing transplantation for severe COPD that continue to manifest airway inflammation. A proof-of-concept analysis of a small number of these patients provided preliminary evidence of increased numbers of iNKT cells and IL-13-positive macrophages in the lung in concert with mucus overproduction (109). Subsequent analysis defined chitinase 1 as a relatively selective marker of M2 macrophage activation and found increased chitinase 1 levels in lung as well as peripheral blood samples in a larger group of COPD patients (112). Here again, the M2 macrophage abnormality was most prominent in those with severe disease. Recent analysis of 15-lipoxygenase-2 (15-LOX-2) as an additional M2 macrophage marker provided similar Results (113). The analysis of the NKT cell-M2 macrophage axis in asthma is still under study. An initial investigation found increased numbers of iNKT cell levels in samples from allergic asthma patients at baseline (114), while others suggest no increase at baseline or an increase mainly with allergen challenge or the presence of severe asthma (115-117). No studies yet assess the level of iNKT cell activation in asthma (or COPD), which is likely to be more informative that counting rare cell populations. An initial analysis also revealed preliminary evidence of IL-13-positive macrophages in BAL samples from a small number of patients with severe asthma (109), but markers of M2 macrophage differentiation that are more stable and expressed at higher levels than cytokines are likely to be more reliable. Increased levels of chitinase $3 \mathrm{~L} 1$ are found in peripheral blood and in lung macrophages (as well as neutrophils and epithelial cells) as a possible sign of M2 macrophage activation in asthma (118). Here again, the abnormality appeared most prominent in the most severe forms of asthma. Initial work also suggests that expression levels of 15 -LOX isoforms (15-LOX-1 versus 15-LOX-2) may be able to discriminate epithelial versus macrophage activation to establish an M2 pattern of immune activation in asthma and COPD (113). Further work is needed to fully define the upstream immune axis for M2 macrophage activation in asthma, and in particular to determine the relative or perhaps synergistic roles of the innate and adaptive immune responses to viruses and allergens. Nonetheless, these clinical biomarkers might be developed as tools for patient stratification that could prove useful for directed immune therapy. 


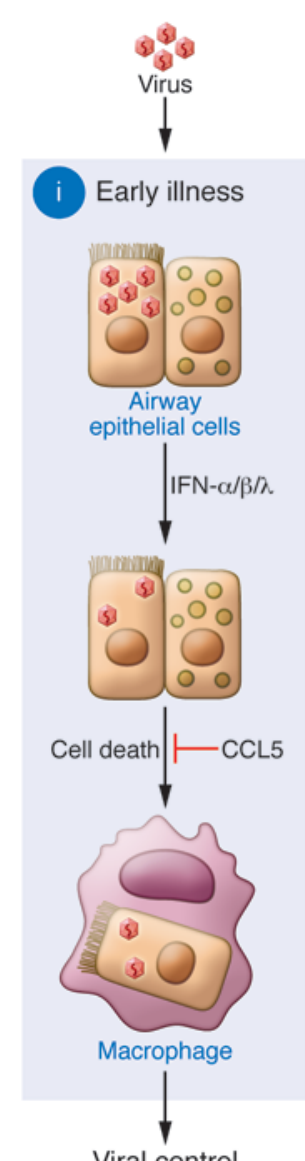

Viral control

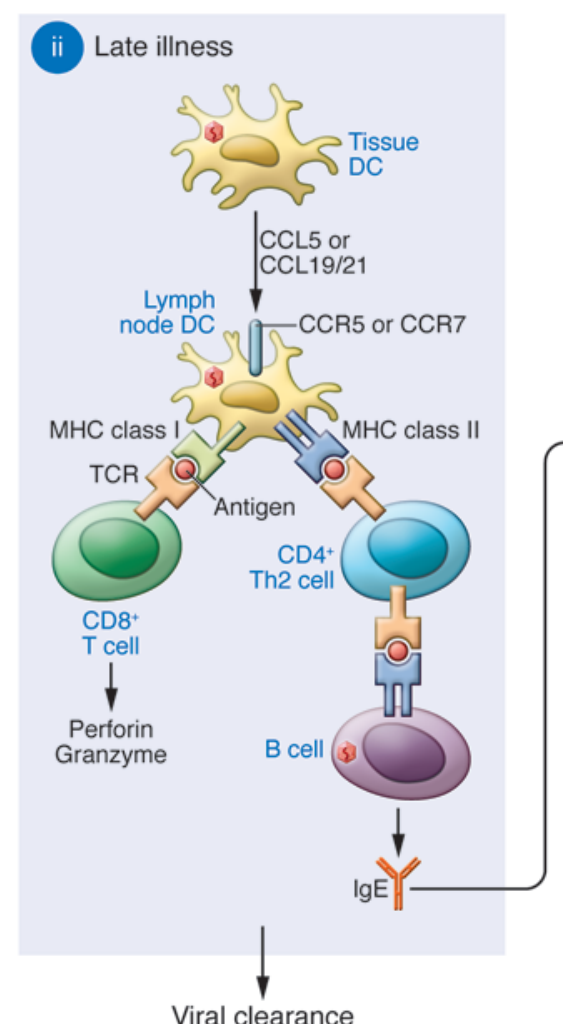

Viral clearance

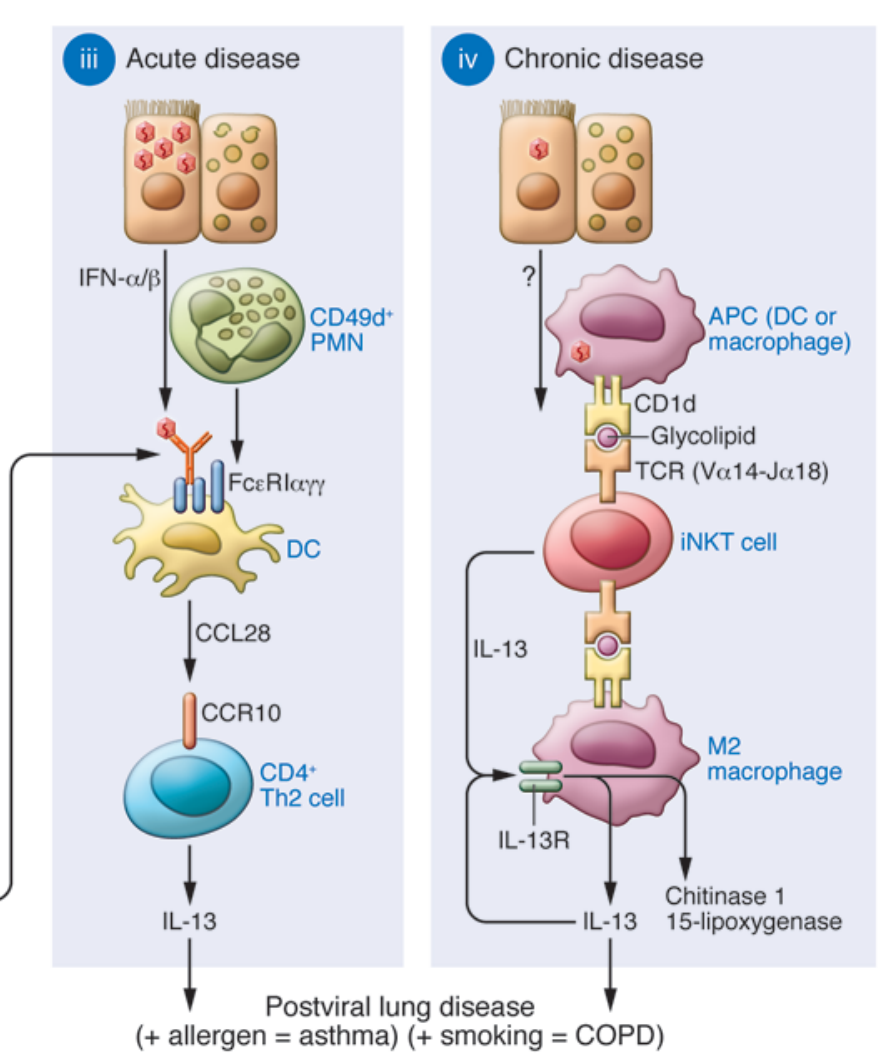

\section{Figure 2}

Immune pathways leading to postviral lung disease. (i) Early viral illness is characterized by the induction of IFN- $\alpha / \beta / \lambda$ and ISG expression to control viral replication and promote cell death and subsequent phagocytosis by CCL5-protected macrophages. (ii) Late viral illness includes lung DC migration to regional lymph nodes for MHC class I-dependent generation of $\mathrm{CD}^{+} \mathrm{T}$ cells and MHC class II-dependent generation of CD4+ Th2 cells and consequent B cell (and, in turn, plasma cell) production of antiviral antibodies (including IgE). (iii) Acute postviral disease is marked by IFN- $\alpha / \beta$ - and CD49+ polymorphonuclear (PMN) cell-dependent upregulation of FceRI expression on resident lung DCs. In turn, FcERI activation by viral antigen and antiviral IgE leads to the production of CCL28 and the recruitment of CCR10-expressing IL-13-producing Th2 cells to the lung. (iv) For chronic postviral disease, virus-activated APCs orchestrate CD1d-dependent glycolipid antigen presentation and consequent activation of iNKT cells. These iNKT cells then interact directly with lung macrophages via IL-13-IL-13R and invariant V $\alpha 14$ TCR-CD1d interactions. These signals lead to increased expression of IL-13R and production of IL-13 that drives a positive feedback loop to amplify IL-13 production and activation of M2 macrophages, marked by chitinase 1 and arachidonate 15-LOX expression. In this immune axis, the airway epithelial cells may also release cytokines (e.g., IL-25, TSLP, and IL-33) that contribute to immune cell activation and chronic inflammatory disease in the form of asthma and COPD. Modified with permission from the American Journal of Respiratory Cell and Molecular Biology (140).

An additional next step for these studies is to define the relationship of these new immune pathways to the recent observations for epithelial cytokines (especially IL-25, TSLP, and IL-33) and innate lymphoid cells that might also participate in IL-13 production in asthma (119-121). Initial work suggests that these pathways are also selectively activated in the $\mathrm{SeV}$ mouse model and in patients with COPD, thereby providing further support for a shared immune mechanism among these conditions $(45,122)$. There is also a need for a comprehensive analysis of the role of viral recognition receptors, including the TLRs (such as TLR3, -7 , and -8), RNA helicases (such as MDA-5 and RIG-I), and NODlike receptors (such as NALP3) that appear active in the antiviral response (123-126). Previous work suggested that activation of TLR3 (as well as TLR7 and MDA5) generally worsened the acute inflammatory response to other viruses, including Th2- dependent inflammation that develops for a short time after RSV infection in mice (94,127-132). However, as noted above, these reports do not address the effect of activation of these viral sensors on chronic obstructive lung disease and therefore do not make a connection between innate immune cell activation and long-term inflammation. As noted below, this immune puzzle needs to be solved to better understand pathogenesis and identify rational and druggable targets for therapeutics in asthma. At present, however, asthma might best be viewed as a complex immune disorder that develops as a function of both innate and adaptive immune responses that contribute to varying degrees in any individual patient. Furthermore, it is intriguing that a distinct innate immune response to viral infection may be linked to the most severe forms of asthma and COPD, in which therapy is most limited and perhaps of greatest priority. 


\section{Improving innate immunity for prevention and cure}

Based on the insights noted above, there appear to be at least two broad opportunities for targeting the innate immune component of asthma to improve outcome. The first of these stems from the role of innate immunity in host defense against inhaled and/or aspirated pathogens. Circumstantial evidence indicates a direct relationship between viral level and both the severity of acute illness and the likelihood of chronic disease $(12,133,134)$. In fact, the capacity of the host to control viral level may be deficient in asthma. Even if there is no antiviral deficiency in asthma, there still stands to be significant benefit for the normal or asthmatic host to improve control over viral infection. The question therefore becomes how best to achieve that goal given the absence of vaccines for viruses that might initiate, propagate, and/or exacerbate asthma. Some have proposed that excessive levels of IFNs might provide therapeutic benefit (135). Indeed, overexpression of IFNencoding genes may protect against experimental infection and inflammatory disease, and administration of recombinant IFN is commonly used for infectious, autoimmune, and cancerous conditions in humans (136). Unfortunately, this approach is limited by toxicity, because disproportionate levels of IFN might harm the normal host (137). It might therefore be more prudent to aim to increase the efficiency of the endogenous IFN signaling pathway and thereby potentiate the benefits of downstream ISG expression (44). Support for this approach can be found in the development of a designer STAT1 molecule (designated STAT1-CC) that markedly increases IFN responsiveness, ISG expression, and control of viral replication (138). The development of therapeutics (particularly small molecules) that mimic this benefit might therefore prevent severe infection and the subsequent inflammatory disease, and indeed, this strategy is well underway (139).

A second therapeutic opportunity is to adjust the innate immune response in a manner that downregulates the harmful effects of inflammation without compromising the benefit of immunity. Of course, this was also the goal of anti-inflammatory approaches derived from the Th2 hypothesis, but recognition and incorpo- ration of the innate immune component should serve for more intelligent design of any new therapy. This approach will still generally depend on identifying druggable targets within the innate immune response and devising therapeutic antagonists to those targets. Indeed, attempts to block IL-25, TSLP, and IL-33 as well as pattern recognition receptors (PRRs) are already being pursued in academic and commercial drug development ventures. In fact, the advanced directive (now in clinical trials) of inhibiting IL-13 itself (as well as IL-5) might be reinterpreted from its Th2 roots, since we now recognize that these cytokines are also primary end products of the innate immune system. Particular challenges for the goal of innate immune blockade include the built-in redundancy of the innate response, the capacity to do harm as well as good when this response is unbalanced, and the requirement for noninvasive clinical biomarkers and imaging approaches to stratify as well as monitor this response in vivo in patients. Initial application of clinical biomarkers for innate immune responses suggests that only a subset of asthma or COPD patients is likely to manifest any given molecular target as a component of their disease $(112,118)$. The application of high-fidelity experimental models in conjunction with validation in these models and in humans will be required to develop new therapeutics and corresponding clinical biomarkers that target the proper subset in asthma or other common inflammatory diseases.

\section{Acknowledgments}

I sincerely thank the members of the Holtzman laboratory for generating the research perspective that underlies this review. The laboratory's research on this topic was supported by grants from the NIH (National Heart, Lung, and Blood Institute and National Institute of Allergy and Infectious Diseases).

Address correspondence to: Michael J. Holtzman, Washington University School of Medicine, Campus Box 8052, 660 South Euclid Avenue, St. Louis, Missouri 63110, USA. Phone: 314.362.8970; Fax: 314.362.9009; E-mail: holtzmanm@wustl.edu.
1. Mosmann TG, Coffman RL. TH1 and TH2 cells: different patterns of lymphokine secretion lead to different functional properties. Annu Rev Immunol. 1989; 7:145-173.

2. Robinson DS, et al. Predominant $\mathrm{T}_{\mathrm{H} 2}$-like bronchoalveolar T-lymphocyte population in atopic asthma. N Engl J Med. 1992;326(5):298-304.

3. Alcorn JF, Crowe CR, Kolls JK. TH17 cells in asthma and COPD. Annu Rev Physiol. 2010;72:495-516.

4. Horka $\mathrm{H}$, et al. The tick salivary protein sialostatin $\mathrm{L}$ inhibits the Th9-derived production of the asthma-promoting cytokine IL-9 and is effective in the prevention of experimental asthma. J Immunol. 2012;188(6):2669-2676.

5. Oertli M, et al. DC-derived IL-18 drives Treg differentiation, murine Helicobacter pylori-specific immune tolerance, and asthma protection. J Clin Invest. 2012;122(3):1082-1096.

6. Poston RN, Chanez P, Lacoste JY, Litchfield T, Lee $\mathrm{TH}$, Bousquet J. Immunohistochemical characterization of the cellular infiltration in asthmatic bronchi. Am Rev Respir Dis. 1992;145(4 pt 1):918-921.

7. Ying S, Durham SR, Corrigan CJ, Hamid Q, Kay AB. Phenotype of cells expressing mRNA for TH2-type (interleukin 4 and interleukin 5) and TH1-type (interleukin 2 and interferon $\gamma$ ) cytokines in bronchoalveolar lavage and bronchial biopsies from atopic asthmatic and normal control subjects. Am J Respir Cell Mol Biol. 1995;12(5):477-487.

8. Hollams EM, et al. Elucidation of asthma pheno- types in atopic teenagers through parallel immunophenotypic and clinical profiling. J Allergy Clin Immunol. 2009;124(3):463-470.

9. Taussig LM, Wright AL, Holberg CJ, Halonen M, Morgan WJ, Martinez FD. Tucson Children's Respiratory Study: 1980 to present. J Allergy Clin Immunol. 2003;111(4):661-675.

10. Morgan WJ, et al. Outcome of asthma and wheezing in the first 6 years of life: follow-up through adolescence. Am J Respir Crit Care Med. 2005; 172(10):1253-1258.

11. Kusel MM, et al. Early-life respiratory viral infections, atopic sensitization and risk of subsequent development of persistent asthma. J Allergy Clin Immunol. 2007;119(5):1105-1110.

12. Castro $\mathrm{M}$, et al. Cytokine response after severe respiratory syncytial virus bronchiolitis in early life. J Allergy Clin Immunol. 2008;122(4):725-733.

13. Thomsen SF, et al. Exploring the association between severe respiratory syncytal virus infection and asthma: a registry-based twin study. Am J Respir Crit Care Med. 2009;179(12):1091-1097.

14. Sigurs N, et al. Asthma and allergy patterns over 18 years after severe RSV bronchiolitis in the first year of life. Thorax. 2010;65(12):1045-1052.

15. Koponen P, Helminen M, Paassilta T, Luukkaala T, Korppi M. Preschool asthma after bronchiolitis in infancy. Eur Respir J. 2012;39(1):76-80.

16. Legg JP, Hussain IR, Warner JA, Johnston SL, Warner JO. Type 1 and Type 2 cytokine imbalance in acute respiratory syncytial virus bronchiolitis. $A m$ J Respir Crit Care Med. 2003;168(6):633-639.

17. Copenhaver CC, et al. Cytokine response patterns, exposure to viruses, and respiratory infections in the first year of life. Am J Respir Crit Care Med. 2004; $170(2): 175-180$.

18. Message SD, et al. Rhinovirus-induced lower respiratory illness is increased in asthma and related to virus load and Th1/2 cytokine and IL-10 production. Proc Natl Acad Sci U S A. 2008;105(36):13562-13567.

19. Olenec JP, et al. Weekly monitoring of children with asthma for infections and illness during common cold seasons. J Allergy Clin Immunol. 2010; 125(5):1001-1006.

20. Rakes GP, et al. Rhinovirus and respiratory syncytial virus in wheezing children requiring emergency care. IgE and eosinophil analyses. Am J Respir Crit Care Med. 1999;159(3):785-790.

21. Jackson DJ, et al. Evidence for a causal relationship between allergic sensitization and rhinovirus wheezing in early life. Am J Respir Crit Care Med. 2012; 185(3):281-285.

22. Papadopoulos NG, et al. Viruses and bacteria in acute asthma exacerbations-a GA2LEN-DARE systematic review. Allergy. 2011;66(4):458-468.

23. Mandelswajg A, Moulin F, Menager C, Rozenberg F, Lebon P, Gendrel D. Underestimation of influenza viral infection in childhood asthma exacerbations. J Pediatr. 2010;157(3):505-506.

24. Nguyen-Van-Tam JS, et al. Risk factors for hospi- 
talisation and poor outcome with pandemic A/ H1N1 influenza: United Kingdom first wave (MaySeptember 2009). Thorax. 2010;65(7):645-651.

25. Kloepfer KM, et al. Increased H1N1 infection rate in children with asthma. Am J Respir Crit Care Med. 2012;185(12):1275-1279.

26. Stein RT, Martinez FD. Respiratory syncytial virus and asthma: still no final answer. Thorax. 2010;65(12):1033-1034.

27. Carroll KN, et al. Influence of maternal asthma on the cause and severity of infant acute respiratory tract infections. J Allergy Clin Immunol. 2012; 129(5):1236-1242.

28. Subrata LS. Interactions between innate antiviral and atopic immunoinflammatory pathways precipitate and sustain asthma exacerbations in children. J Immunol. 2009;183(4):2793-2800.

29. Holt PG, et al. Towards improved prediction of risk for atopy and asthma amongs preschoolers: a prospective cohort study. J Allergy Clin Immunol. 2010; 125(3):653-659.

30. Strachan DP. Hay fever, hygiene, and household size. BMJ. 1989;299(6710):1259-1260.

31. Holt PG, et al. Genetic 'risk' for atopy is associated with delayed postnatal maturation of T-cell competence. Clin Exp Allergy. 1992;22(12):1093-1099.

32. Ege MJ, et al. Exposure to environmental microorganisms and childhood asthma. $N$ Eng J Med. 2011;364(8):701-709.

33. Holtzman MJ, Sampath D, Castro M, Look DC, Jayaraman $S$. The one-two of $\mathrm{T}$ helper cells: does interferon- $\gamma$ knockout the Th2 hypothesis for asthma? Am J Respir Cell Mol Biol. 1996;14(4):316-318.

34. Holtzman MJ. Where are the gaps in asthma research? A counter-perspective. J Allergy Clin Immunol. 2003;111(2):244-247.

35. Holtzman MJ. Drug development for asthma. Am J Respir Cell Mol Biol. 2004;29(2):163-179.

36. Sumino K, et al. Antiviral IFN- $\gamma$ responses of monocytes at birth predict respiratory tract illness in the first year of life. J Allergy Clin Immunol. 2012; 129(5):1267-1273.e1.

37. Miksch JS, Szecsenyi J, Wieseler B, Grouven U, Kaiser T, Schneider A. Montelukast as add-on therapy to inhaled corticosteroids in the treatment of mild to moderate asthma: a systematic review. Thorax. 2008;63(5):453-462.

38. Busse WW, et al. Randomized trial of omalizumab (anti-IgE) for asthma in inner-city children. N Engl JMed. 2011;364(11):1005-1015.

39. Wenzel S, Wilbraham D, Fuller R, Getz EB, Longphre M. Effect of an interleukin-4 variant on late phase asthmatic response to allergen challenge in asthmatic patients: Results of two phase 2 a studies. Lancet. 2007;370(9596):1396-1398.

40. Corren J, et al. A randomized, controlled, phase 2 study of AMG 317, an IL-4Ra antagonist, in patients with asthma. Am J Respir Crit Care Med. 2010; 181(8):788-796.

41. Corren J. Anti-interleukin-5 antibody therapy in asthma and allergies. Curr Opin Allergy Clin Immunol. 2011;11(6):565-570.

42. Corren J, et al. Lebrikizumab treatment in adults with asthma. NEnglJ Med. 2011;365(12):1088-1098.

43. Holtzman MJ, et al. Immunity, inflammation, and remodeling in the airway epithelial barrier: epithelial-viral-allergic paradigm. Physiol Rev. 2002; 82(1):19-46.

44. Zhang Y, Hinojosa ME, Holtzman MJ. Viral and host strategies to take advantage of the innate immune response. Am J Respir Cell Mol Biol. 2010; 43(5):507-510

45. Byers DE, et al. Defining the role of the key cytokines (TSLP, IL-25, and IL-33) controlling IL-13 production and chronic obstructive lung disease under experimental and clinical conditions. Am J Respir Crit Care Med. 2012;184:A1294.

46. Shornick LP, et al. Airway epithelial versus immune cell Stat 1 function for innate defense against respiratory viral infection. J Immunol. 2008; 180(5):3319-3328.

47. Holtzman MJ, Patel D, Kim H, You Y, Zhang Y Hypersusceptibility to respiratory viruses as a shared mechanism for asthma, COPD, and CF. Am J Respir Cell Mol Biol. 2011;44(6):739-742.

48. Dupuis $S$, et al. Impaired response to interferon$\mathrm{a} / \mathrm{b}$ and lethal viral disease in human STAT1 deficiency. Nat Genet. 2003;33(3):388-391.

49. Papadopoulos NG, Stanciu LA, Papi A, Holgate ST, Johnston SL. A defective type I response to rhinovirus in atopic asthma. Thorax. 2002;57(4):328-332.

50. Bufe A, Gehlhar K, Grage-Griebenow E, Ernst M. Atopic phenotype in children is associated with decreased virus-induced interferon-alpha release. Int Arch Allergy Immunol. 2002;127(1):82-88.

51. Guerra S, Lohman I, Halonen M, Martinez F, Wright A. Reduced interferon gamma production and soluble CD14 levels in early life predict recurrent wheezing by 1 year of age. Am J Respir Crit Care Med. 2004;169(1):70-76.

52. Macaubas $\mathrm{C}$, et al. Association between antenatal cytokine production and the development of atopy and asthma at age 6 years. Lancet. 2003; 362(9391):1192-1197.

53. Aberle JH, Aberle SW, Rebhandl W, Pracher E, Kundi M, Popow-Kraupp T. Decreased interferongamma response in respiratory syncytial virus compared to other respiratory viral infections in infants. Clin Exp Immunol. 2004;137(1):146-150.

54. Gelhar K, Bilitewski C, Reinitz-Rademacher K, Rohde G, Bufe A. Impaired virus-induced interferon-alpha 2 release in adult asthmatic patients. Clin Exp Allergy. 2006;36(3):331-337.

55. Gern J, et al. Bidirectional interactions between viral respiratory illnesses and cytokine responses in the first year of life. J Allergy Clin Immunol. 2006; 117(1):72-78.

56. Ly NP, et al. Cord blood cytokines and acute lower respiratory illnesses in the first year of life. Pediatrics. 2007;119(1):e171-e178.

57. Walter MJ, Look DC, Tidwell RM, Roswit WT, Holtzman MJ. Targeted inhibition of interferon-gdependent ICAM-1 expression using dominant-negative Stat1. J Biol Chem. 1997;272(45):28582-28589.

58. Look DC, et al. Direct suppression of Stat 1 function during adenoviral infection. Immunity. 1998; 9(6):871-880

59. Lo MS, Brazas RM, Holtzman MJ. Respiratory syncytial virus nonstructural proteins NS1 and NS2 mediate inhibition of Stat2 expression and type I interferon responsiveness. J Virol. 2005; 79(14):9315-9319.

60. Wark PA, et al. Asthmatic bronchial epithelial cells have a deficient innate immune response to infection with rhinovirus. J Exp Med. 2005;201(6):937-947.

61. Contoli M, et al. Role of deficient type III interferon-1 production in asthma exacerbations. Nat Med. 2006; 12(9):1023-1026.

62. Cakebread JA, et al. Exogenous IFN-b has antiviral and anti-inflammatory properties in primary bronchial epithelial cells from asthmatic subjects exposed to rhinovirus. J Allergy Clin Immunol. 2011; 127(5):1148-1154.

63. Harada M, et al. Functional polymorphism in the suppressor of cytokine signaling 1 gene associated with adult asthma. Am J Respir Cell Mol Biol. 2007;36(4):491-496.

64. Torgerson DG, et al. Meta-analysis of genome-wide association studies of asthma in ethnically diverse North American populations. Nat Genet. 2011; 43(9):887-893.

65. Zheng S, et al. Impaired innate host defense causes susceptibility to respiratory virus infections in cystic fibrosis. Immunity. 2003;18(5):619-630.

66 . Schneider D, et al. Increased cytokine resonse of rhinovirus-infected airway epithelial cells in chronic obstructive pulmonary disease. Am J Respir Crit Care Med. 2010;182(3):332-340.

67. Mallia P, et al. Experimental rhinovirus infection as a human model of chronic obstructive pulmonary disease exacerbation. Am J Respir Crit Care Med. 2011;183(6):734-742.

68. Bochkov YA, Hanson KM, Keles S, BrockmanSchneider RA, Narjour NN, Gern JE. Rhinovirusinduced modulation of gene expression in bronchial epithelial cells from subjects with asthma. Mucosal Immunol. 2010;3(1):69-80.

69. Lopez-Souza N, et al. In vitro susceptibility to rhinovirus infection is greater for bronchial than for nasal airway epithelial cells in human subjects. J Allergy Clin Immunol. 2009;123(6):1384-1390.

70. DeMore JP, et al. Similar colds in subjects with allergic asthma and nonatopic subjects after inoculation with rhinovirus-16. J Allergy Clin Immunol. 2009; 124(2):245-252.

71. Sampath D, Castro M, Look DC, Holtzman MJ. Constitutive activation of an epithelial signal transducer and activator of transcription (Stat1) pathway in asthma. J Clin Invest. 1999;103(9):1353-1361.

72. Bullens DM, et al. Type III IFN-lambda mRNA expression in sputum of adult and school-aged asthmatics. Clin Exp Allergy. 2008;38(9):1459-1467.

73. Fort MM, et al. IL-25 induces IL-4, IL-5, and IL-13 pathologies and Th2-associated pathologies in vivo. Immunity. 2001;15(6):985-995.

74. Schmitz J, et al. IL-33, an interleukin-1-like cytokine that signals via the IL-1 receptor-related protein ST2 and induces T helper type-2 associated cytokines. Immunity. 2005;23(5):479-490.

75. Wang Y-H, et al. IL-25 augments type 2 immune responses by enhancing the expansion and functions of TSLP-DC-activated Th2 memory cells. JExp Med. 2007;204(8):1837-1847.

76. Kato A, Favoreto S, Avila PC, Schleimer RP. TLR3and Th2 cytokine-dependent production of thymic stromal lymphopoietin in human airway epithelial cells. J Immunol. 2007;179(2):1080-1087.

77. Ying S, et al. Expression and cellular provenance of thymic stromal lymphopoietin and chemokines in patients with severe asthma and chronic obstructive pulmonary disease. J Immunol. 2008; 181(4):2790-2798.

78. Moussion C, Ortega N, Girard JP. The IL-1-like cytokine IL-33 is constitutively expressed in the nucleus of endothelial cells and epithelial cells in vivo: a novel "alarmin". PloS One. 2008;3(10):e3331.

79. Terashima A, et al. A novel subset of mouse NKT cells bearing IL-17 receptor B responds to IL-25 and contributes to airway hyperreactivity. $J$ Exp Med. 2008;205(12):2727-2733.

80. Demehri S, Morimoto M, Holtzman MJ, Kopan R. Skin-derived TSLP triggers progression from epidermal-barrier defects to asthma. PLoS Biol. 2009;7(5):e1000067.

81. Zhou B, et al. Thymic stromal lymphopoietin as a key initiator of allergic airway inflammation in mice. Nat Immunol. 2005;6(10):1047-1053.

82. Ballantyne SJ, et al. Blocking IL-25 prevents airway hyperresponsiveness in allergic asthma. J Allergy Clin Immunol. 2007;120(6):1324-1331.

83. Kearley J, Buckland KF, Mathie SA, Lloyd CM. Resolution of allergic inflammation and airway hyperreactivity is dependent upon disruption of the T1/ ST2-IL-33 pathway. Am J Respir Crit Care Med. 2009;179(9):772-781.

84. Liu X, Li M, Wu Y, Zhou Y, Zeng L, Huang T. AntiIL-33 antibody treatment inhibits airway inflammation in a murine model of allergic asthma. Biochem Biophys Res Commun. 2009;386(1):181-185.

85. Fallon PG, et al. Identification of an interleukin (IL)-25-dependent cell population that provides IL-4, IL-5, and IL-13 at the onset of helminth explusion. J Exp Med. 2006;203(4):1105-1116.

86. Moro $\mathrm{K}$, et al. Innate production of TH2 cytokines 
by adipose tissue-associated c-Kit + Sca- $1+$ lymphoid cells. Nature. 2009;463(7280):540-544.

87. Neill DR, et al. Nuocytes represent a new innate effector leukocyte that mediates type-2 immunity. Nature. 2010;464(7293):1367-1370.

88. Saenz SA, et al. IL-25 elicits a multi-potent progenitor cell population that promotes Th2 cytokine responses. Nature. 2010;464(7293):1362-1366

89. Barlow JL, et al. Innate IL-13-producing nuocytes arise during allergic lung inflammation and contribute to airways hyperreactivity. J Allergy Clin Immunol. 2011;129(1):191-198.

90. Price AE, et al. Systemically dispersed innate IL-13 expressing cells in type 2 immunity. Proc Natl Acad SciU S A. 2011:107(25):11489-11494.

91. Chang Y, et al. Innate lymphoid cells mediate influenza-induced airway hyper-reactivity independently of adaptive immunity. Nat Immunol. 2011 12(7):631-638

92. Graham BS, Perkins MD, Wright PF, Karzon DT Primary respiratory syncytial virus infection in mice. J Med Virol. 1988;26(2):153-162.

93. Bartlett NW, et al. Mouse models of rhinovirusinduced disease and exacerbation of allergic airway inflammation. Nat Med. 2008;14(2):199-204.

94. Wang Q, et al. MDA5 and TLR3 initiate proinflammatory signaling pathways leading to rhinovirus-induced airways inflammation and hyperresponsiveness. PLoS Pathog. 2011; 7(5):e1002070.

95. Bochkov YA, et al. Molecular modeling, organ culture and reverse genetics for a newly identified human rhinovirus C. Nat Med. 2011;17(5):627-632.

96. Holt PG, Vines J, Bilyk N. Effect of influenza virus infection on allergic sensitization to inhaled antigen in mice. Int Arch Allergy Appl Immunol. 1988; 86(1):121-123.

97. Schwarze J, Hamelmann E, Bradley KL, Takeda $\mathrm{K}$, Gelfand EW. Respiratory syncytial virus infection Results in airway hyperresponsiveness and enhanced airway sensitization to allergen. J Clin Invest. 1997;100(1):226-233.

98. Al-Garawi A, et al. Shifting of immune responsiveness to house dust mite by influenza $\mathrm{A}$ infection: genomic insights. J Immunol. 2012;188(2):832-843.

99. Walter MJ, Morton JD, Kajiwara N, Agapov E, Holtzman MJ. Viral induction of a chronic asthma phenotype and genetic segregation from the acute response. J Clin Invest. 2002;110(2):165-175.

100.Patel AC, et al. Genetic segregation of airway disease traits despite redundancy of chloride channe calcium-activated (CLCA) family members. Physiol Genomics. 2006;25(3):502-513.

101. Tyner JW, et al. Blocking airway mucous cell metaplasia by inhibiting EGFR antiapoptosis and IL-13 transdifferentiation signals. J Clin Invest. 2006 116(2):309-321.

102.Kohlmeier JE, Cookenham T, Roberts AD, Miller SC, Wodland DL. Type I interferons regulate cytolytic activity of memory CD8+ $\mathrm{T}$ cells in the lung airway during respiratory virus challenge. Immunity. 2010;33(1):95-105.

103. Tyner JW, et al. CCL5-CCR5 interaction provides antiapoptotic signals for macrophage survival during viral infection. Nat Med. 2005;11(11):1180-1187.

104.Grayson $\mathrm{MH}$, et al. Controls for lung dendritic cell maturation and migration during respiratory viral infection. J Immunol. 2007;179(3):1438-1448

105. Kohlmeier JE, et al. CXCR3 directs antigen-specific effector CD4+ $\mathrm{T}$ cell migration to the lung during parainfluenza virus infection. J Immunol. 2009;183(7):4378-4384

106. Sandau MM, Kohlmeier JE, Woodland DL, Jameson SC. IL-15 regulates both quantitative and qualitative features of the memory CD8 T cell pool. I Immunol. 2010;184(1):35-44.

107. Grayson $\mathrm{MH}$, et al. Induction of high-affinity IgE receptor on lung dendritic cells during viral infection leads to mucous cell metaplasia. J Exp Med. 2007;204(11):2759-2769.

108. Cheung DS, et al. Cutting Edge: CD49d+ neutrophils induce FceRI expression on lung dendritic cells in a mouse model of postviral asthma. J Immunol. 2010;185(9):4983-4987.

109. Kim EY, et al. Persistent activation of an innate immune response translates respiratory viral infection into chronic inflammatory lung disease. Nat Med. 2008;14(6):633-640.

110. Benoit LA, Holtzman MJ. New immune pathways from chronic post-viral lung disease. Ann NY Acad Sci. 2010;1183:195-210.

111.Vasudev M, et al. Expression of high-affinity IgE receptor on human peripheral blood dendritic cells in children. PloS One. 2012;7(2):e32556

112.Agapov E, et al. Macrophage chitinase 1 stratifies chronic obstructive lung disease. Am J Respir Cell Mol Biol. 2009;41(4):379-384.

113. Byers DE, et al. Development of 15-lipoxygenase(15-LOX1) and 15-lipoxygenase-2 (15-LOX2) as markers to stratify epithelial versus macrophage activities in chronic obstructive lung diseases. $A m$ Respir Crit Care Med. 2012;184:A1427.

114.Akbari O, et al. CD4 ${ }^{+}$invariant T-cell-receptor ${ }^{+}$ natural killer T cells in bronchial asthma. $N$ Engl J Med. 2006;354(11):1117-1129.

115.Vijayanand $\mathrm{P}$, et al. Invariant natural killer T cells in asthma and chronic obstructive pulmonary disease. New Engl J Med. 2007;356(14):1410-1422.

116. Reynolds C, et al. Natural killer T cells in bronchial biopsies from human allergen challenge model of allergic asthma. J Allergy Clin Immunol. 2009; 124(4):860-862.

117. Matangkasombut $P$, et al. Natural killer T cells in the lungs of patients with asthma. J Allergy Clin Immunol. 2009;123(5):1181-1185

118.Chupp GL, et al. A chitinase-like protein in the lung and circulation of patients with severe asthma N Engl J Med. 2007;357(20):2016-2027.

119.Smithgall MD, Comeau MR, Yoon BP, Kaufman D, Armitage R, Smith DE. IL-33 amplifies both Th1and Th2-type responses through its activity on human basophils, allergen-reactive Th 2 cells, iNKT and NK cells. Int Immunol. 2008;20(8):1019-1030.

120. Kurowska-Stolarska M, et al. IL-33 amplifies the polarization of alternatively activated macrophages that contribute to airway inflammation. J Immunol. 2009;183(10):6469-6477.

121. Oboki K, et al. IL-33 is a crucial amplifier of innate rather than acquired immunity. Proc Natl Acad Sci US A. 2010;107(43):18581-18586.

122. Byers DE, et al. A distinct population of non- $B$, non- $T$ (NBNT) cells express high levels of IL-13 during acute and chronic airway disease after viral infection. Am J Respir Crit Care Med. 2009;179(2):A4293.
123.Thomas PG, Dash P, Aldridge JR, Ellebedy AH, Doherty PC, Kanneganti T. The intracellular sensor NLRP3 mediates key innate and healing responses to influenza A virus via the regulation of caspase- 1 . Immunity. 2009;30(4):566-575.

124.Ichinohe T, Lee HK, Ogura Y, Flavell RA, Iwasaki A. Inflammasome recognition of influenza virus is essential for adaptive immune responses.J Exp Med. 2009;206(1):79-87.

125.Allen IC, et al. The NLRP3 inflammasome mediates in vivo innate immunity to influenza A virus through recognition of viral RNA. Immunity. 2009; 30(4):556-565

126. Gitlin L, et al. Melanoma differentiation-associated gene 5 (MDA5) is involved in the innate immune response to Paramyxoviridae infection in vivo. PLoS Pathog. 2010;6(1):e1000734.

127. Wang T, Town T, Alexopoulou L, Anderson JF, Fikrig E, Flavell RA. Toll-like receptor 3 mediates West Nile virus entry into the brain causing lethal encephalitis. Nat Med. 2004;10(12):1366-1373.

128.Le Goffic R, et al. Detrimental contribution of the Toll-like receptor (TLR) 3 to influenza A virusinduced acute pneumonia. PLoS Pathog. 2006; 2(6):e53.

129. Gowen BB, et al. TLR3 deletion limits mortality and disease severity due to Phlebovirus infection. J Immunol. 2006;177(9):6301-6307.

130. Hutchens $\mathrm{M}$, et al. TLR3 increases disease morbidity and mortality from vaccinia infection. J Immunol. 2008;180(1):483-491.

131. Rudd BD, et al. Deletion of TLR3 alters the pulmonary immune environment and mucus production during respiratory syncytial virus infection. J Immunol. 2006;176(3):1937-1942.

132.Lukacs NW, Smit JJ, Mukherjee S, Morris SB, Nunez G, Lindell DM. Respiratory virus-induced TLR7 activation controls IL-17 associated increased mucus via IL-23 regulation. J Immunol. 2010; 185(4):2231-2239.

133. Sigurs N, et al. Severe respiratory syncytial virus bronchiolitis in infancy and asthma and allergy at age 13. Am J Respir Crit Care Med. 2005;171(2):137-141.

134.DeVincenzo JP, et al. Viral load drives disease in humans experimentally infected with respiratory syncytial virus. Am J Respir Crit Care Med. 2010; 182(10):1305-1314

135. Holgate ST. Epithelium dysfunction in asthma. J Allergy Clin Immunol. 2007;120(6):1233-1244.

136. Borden EC, et al. Interferons at age 50: past, current and future impact on biomedicine. Nat Rev Drug Discov. 2007;6(12):975-990.

137. Biggioggero M, Gabbriellini L, Meroni PL. Type I interferon therapy and its role in autoimmunity. Autoimmunity. 2010;43(3):248-254

138. Zhang Y, et al. Modification of the Stat 1 SH2 domain broadly improves interferon efficacy in proportion to $\mathrm{p} 300 / \mathrm{CREB}-$ binding protein coactivator recruitment. JBiol Chem. 2005;280(40):34306-34315.

139.Patel DA, Patel AC, Nolan WC, Zhang Y, Holtzman MJ. High throughput screening for small molecule enhancers of the interferon signaling pathway to drive next-generation antiviral drug discovery. PloS One. 2012;7(5):e36594.

140.Byers DE, Holtzman MJ. Alternatively activated macrophages as cause or effect in asthma. Am J Respir Cell Mol Biol. 2010;43(1):1-4. 